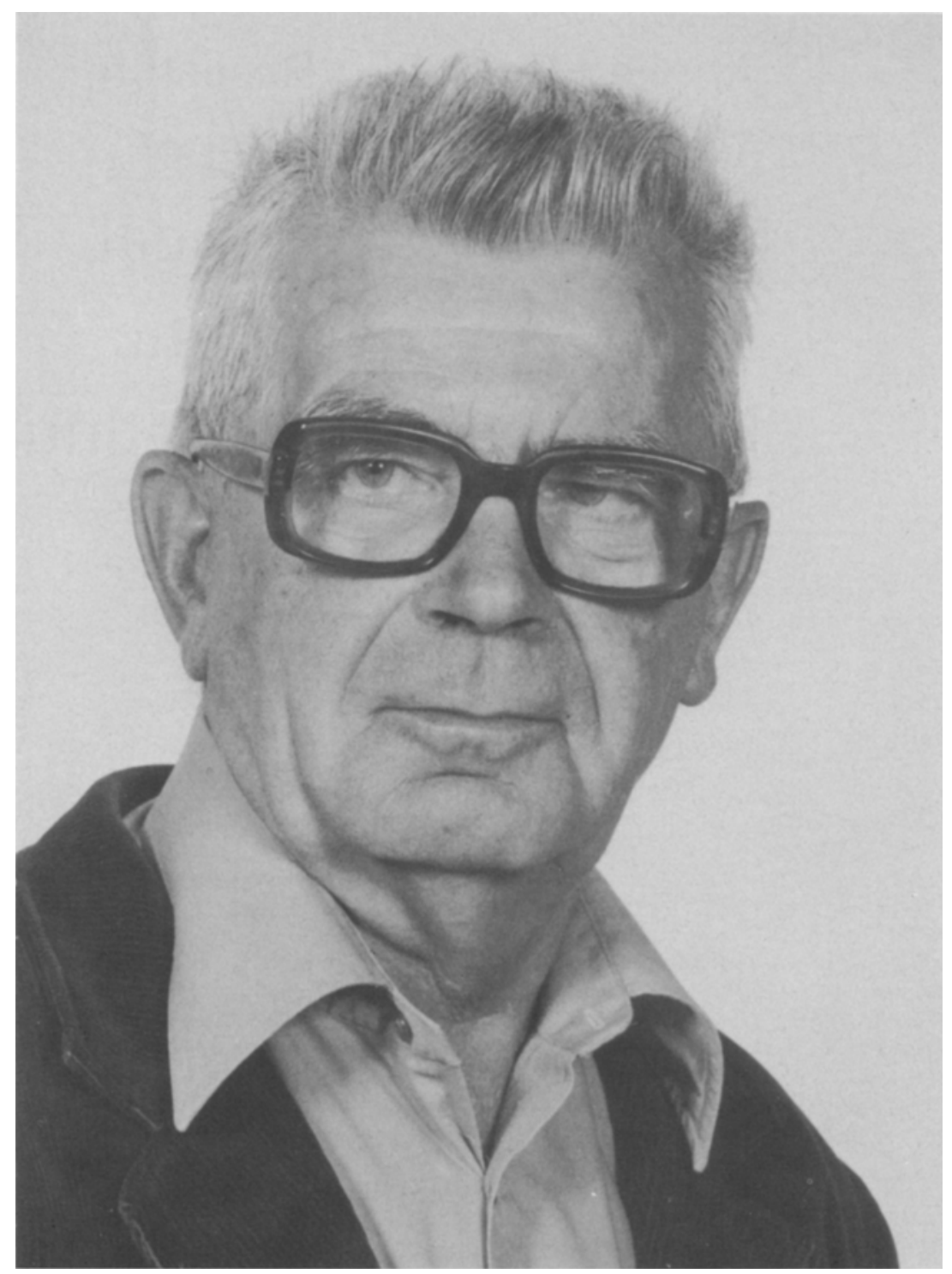

Professor Dr. L. J. F. Broer 


\title{
A brief summary of L.J.F. Broer's work up till his retirement
}

\author{
F.W. SLUIJTER* and L. VAN WIJNGAARDEN ${ }^{* *}$ \\ *Dept. Applied Physics, Eindhoven University of Technology, Eindhoven, \\ The Netherlands and ${ }^{* *}$ Dept. Applied Physics \& Dept. of Mech. Engineering, \\ Twente University of Technology, Enschede, The Netherlands
}

This special issue of Applied Scientific Research is in honour of Professor L.J.F. Broer on the occasion of his retirement as Professor of Theoretical Physics at the Technological University at Eindhoven, the Netherlands.

In these opening pages we want to summarize briefly some of the highlights of his professional life, as this has developed thus far. We know that retiring as Professor will not bring Broer's scientific activities to a stop. A review therefore can only give a momentary picture, but the occasion seems a good one to make such a survey. Especially now this can be done in the pages of this journal which has had the pleasure of publishing many of his papers and which he has served for many years in various capacities, notably as Editor in Chief from 1960-1972.

Lambertus Johannes Folkert Broer was born on January 17, 1916. His father taught mathematics in high school, having reached that position by passing, starting from the level of teacher in elementary school, the numerous professional examinations required then and now in Holland and known as 'K-examinations'. No doubt the young Bert Broer inherited his love and taste for mathematics from his father. When later on the latter visited with his son in Delft at Christmas time, they used to do problems in descriptive geometry together.

In the first half of the 1930's L.J.F Broer was registered in the University of Amsterdam as a student in the Department of Mathematics \& Physics. He was to stay in Amsterdam till 1949. He studied theoretical physics under J.D. v.d. Waals jr. (whose father formulated the famous equation) and subsequently prepared a thesis working with C.J. Gorter (then at Amsterdam and later at the Kamerlingh Onnes Laboratory at Leyden) on paramagnetic relaxation.

This thesis was completed before the end of World War II but since as a result of the German occupation academic life had come to a stop, Boer received his $P h . D$. just after the end of the war in 1945. During the German occupation Broer was taken prisoner for a couple of days but he was set free thanks to the efforts of his wife Lina who managed to provide some impressive official papers. For a while Broer considered accepting a job with the Philips Physical Laboratories at Eindhoven, but the liberation, in 1944, of the southern part of the Netherlands, making this inaccessible from the north, 
prevented the realization of this. Instead Broer remained in Amsterdam where he became Lector (Associate Professor) in Physics at the University of Amsterdam in 1946. He taught Maxwell theory whereas his research was centered around his work with C.J. Gorter on paramagnetic relaxation. In 1948 he spent a couple of months with Van Vleck at Harvard University where he tried to unravel some problems encountered in the calculation of magnetic susceptibilitiest (this work was eventually published in 1951 [29]).

In this period a call came from the Technological University at Delft to join them as Professor in Aero- and Hydrodynamics. Delft had had in the person of J.M. Burgers an excellent experience in appointing a young bright theoretical physicist as professor in fluid dynamics. It is for sure that Broer was no less a success. He was appointed in 1949 and while he avoided any hard fluid dynamics in his inaugural lecture [25] to conceal his lack of knowledge there, he mastered the new subject in an amazingly short time. Already in 1950 papers on fluid mechanics started to appear. In Delft, as before in Amsterdam and later in Eindhoven, Broer has been very prolific. Altogether he published some 120 papers and articles. He seldom dealt with specific problems but rather with broad phenomena like shock waves or water waves. His aim is always to bring out the basic physics of these phenomena, their mathematical description and the various methods available for their analysis.

It would be impossible, given the number of them, to discuss here all of Broer's papers. They are listed at the end. We mention here only a few of them, which in particular brought Broer wide recognition and an international reputation among fluid dynamicists.

His first fluid mechanics paper written in Delft is [26] 'On the propagation of energy in linear conservative waves'. This paper already shows many of the features so characteristic in Broer's work. It does not deal with any specific kind of waves, although of course examples are given to illustrate the general theory, but rather with all waves which are both linear and conservative. In one spatial dimension $x$ such a wave can be represented by the Fourier integral

$$
\int F(k) \exp i\{k x-\Omega(k) t\} \mathrm{d} k
$$

where $\Omega(k)$ is the angular frequency as a function of the wave number $k$. The relation between $\Omega$ and $k$ results from seeking solutions of the pertinent wave equation of the form $\exp i(k x-\Omega t)$ and is called the dispersion equation. In the paper Broer first shows by application of the method of stationary phase that the main contribution to (1) at a given $x$ and $t$ is a harmonic wave

$$
a \exp i\{\bar{k} x-\Omega(\bar{k}) t\}
$$

\footnotetext{
$\uparrow$ Numbers in brackets refer to the list of Broer's publications at the end of this article.
} 
$\bar{k}$ being given by

$$
\frac{x}{t}=v=\frac{\partial \Omega(k)}{\partial k} .
$$

The velocity $v$ is the so-called group velocity and appears, as Broer subsequently shows, also to be the velocity at which energy propagates. Broer then poses the interesting question why only the dispersion equation, which reflects a kinematic property of the wave, is needed to determine the velocity with which a dynamic quantity like energy propagates. As an answer to this question he shows that the condition of energy conservation limits the possible forms of the energy density, associated with a given dispersion equation, to such an extent that the energy velocity is always identical with the group velocity. This paper is mentioned in many textbooks on wave motions (e.g. Wehausen and Laitone, Handbuch der Physik III, Springer 1960).

The dynamics of gases attracted Broer's attention very early in Delft. $\mathrm{He}$ studied in particular the complications which arise from the absence of thermodynamic equilibrium. This can be summarized as relaxation gasdynamics. After a series of papers $[27,31,35,37,38]$ this culminated in a very well-known paper [51] entitled 'Characteristics of the equations of motion of a reacting gas'. This lucid paper is a typical 'Broer paper'. To the ingredients already mentioned is now added the circumstance that he has come across somebody making an essential error in the interpretation of certain theoretical results. In this case E.L. Resler from Cornell University who drew an erroneous conclusion from formulations in characteristic form of the equations of motion of a reacting gas. In such a gas, let $q$ be a parameter characterizing the chemical composition. If the gas is left to itself for a sufficiently long time $q$ reaches an equilibrium value, $q_{e}$ say. If because of changes, e.g. by a wave motion, of the thermodynamic variables as pressure and density there is no equilibrium, the local value $q$ tends to $q_{e}$ according to a rate equation of the type

$$
\frac{\mathrm{d} q}{\mathrm{~d} t}=-\alpha\left(q-q_{e}\right)
$$

For small amplitude pressure waves of the form exp $i(k x-\omega t)$ travelling through the reacting gas, the propagation speed $\omega / k$ tends to different limits according to $\omega \rightarrow \infty$ or $\omega \rightarrow 0$. In the first case the frequency is so high that no reaction takes place at all. The reaction is frozen and the corresponding speed $\omega / k, c_{f}$ say, is called the frozen sound speed. When $\omega \rightarrow 0$ there is always time for the reaction to take place and $q$ will always be at its equilibrium value $c_{e}$. The associated wave speed is called the equilibrium speed. If one asks for the speed with which a disturbance, e.g. generated by a piston, travels into an initially quiescent mixture, one could assume that this sound speed equals $c_{e}$ when the constant $\alpha$ in (3) is infinitely large, $c_{f}$ when $\alpha$ is zero and varies between these values when $\alpha$ goes from infinity to zero. Such a 
conclusion was in fact drawn by Resler from manipulations of the equations of motion closely related to writing them in characteristic forms. Closely, but not entirely so. Broer choosing his dependent variables ingeniously, wrote in [51] the gasdynamic equations correctly in characteristic form and showed that for any finite $\alpha$ the speed of the front is $c_{f}$. Only in the limit $\alpha \rightarrow \infty$ is the speed $c_{e}$. Broer goes on in this paper with explaining what Resler did wrong and he ends the paper with a lucid exposition in which everything is made clear and plausible. This beautiful paper is the only one which Broer published in the 'Journal of Fluid Mechanics'. When Broer has an idea he is confident that it is a good one and worth pursuing. He works it out and writes it up and is eager to go on with something else. Now some journals require their authors to do a painstaking investigation regarding related work and the associated references, a precise determination of what is new and what has been done earlier, be it sometimes in another way. All this requires as a rule tedious and time consuming work, which Broer dislikes. Ideally suited to his style are journals like 'Applied Scientific Research' which far from being uncritical, do nevertheless not enforce on their authors the above mentioned load.

For this reason however sometimes important contributions by Broer have escaped the attention of other people working in the field of fluid dynamics. Not however, paper [51] and when P.P. Wegener (who contributes to this volume) envisaged a book on nonequilibrium gasdynamics it was no wonder that he asked Broer to write the introductory chapter [84].

Always interested in new developments, Broer became in the late fifties involved in a new field of endeavour, namely magnetohydrodynamics. He judged the problems arising there worthwhile and induced students to work on them. He became a frequent visitor of the F.O.M Institute for Plasma Physics near Utrecht. One paper from this period deserves to be mentioned in particular. It [58] deals with the motion of a charged particle in a slowly (in time or spatial) varying magnetic field. In particular Broer investigated whether the centre of the gyrating motion undergoes a net displacement as time goes on. Physically this problem is related to the theory of adiabatic invariants, mathematically it has to do with asymptotic solutions of the wave equation. Very generously Broer allowed the name of one of the present writers (L.v.W.) to be printed on this paper because of a very modest contribution to a specific example at the end of the paper. The way in which Broer dealt with the important questions involved here found its way both to textbooks on plasma physics and on applied mathematics (J.D. Cole Perturbation Methods in Applied Mathematics, Blaisdell, 1968).

As testified by the list of Broer's publications, the papers mentioned form only a very small part of a long list. As a teacher Broer is most effective in informal discussions, often (in Delft) at the coffee table among students in the laboratory in the Ezelsveldlaan, and in discussions with students whose master's or Ph.D. thesis he supervises. He has the rare gift of indicating which way to go to a student without solving the problem for him. Although 
fluid mechanics occupied at the time (as it still does) only a modest corner both in the department of Mechanical Engineering and in that of Applied Physics, Broer attracted quite a few students, who liked him as an easy going friendly professor. Apart from teaching them fluid mechanics, he went out skating with them on winterdays when canals were frozen, took them out sailing in his boat and played chess against the whole lot of them thereby beating most of them.

Of course, working in a Technological University brought him in contact with engineers. From time to time he became involved. So we find among his Delft papers one dealing with waterhammer [48], one dealing with the efficiency of combustion engines [33], one on the ventilation of traffic tunnels [45] and one on cyclones [34]. The specific way in which a physicist looks at things had not come (and has not even today) to many fluid mechanical devices in engineering. A good example is the so-called cyclone, a centrifuge type device to separate small particles like coal dust from gas. At the time Broer came to Delft all there was, were a few rules of thumb and a lot of experimental data. Encouraged by his engineering colleagues Broer gave some thought to this device which resulted in an attempt [34] to describe what happens in fluid mechanical terms. Later, Broer, when recalling this episode, used to tell with a chuckle that he was since then considered an expert on cyclones without ever having seen one!

Bert Broer does not lack interest in the way a university is organized and governed. Sometimes on the verge of accepting a deanship he was eventually scared away when he realized how much of his time would be involved. He was willing, nevertheless, to serve the Delft Technological University as conrector in 1960 , a job which he thoroughly enjoyed. Remarkably enough, the Rector under which he served was R. Koning also a distinguished theoretical physicist. Never before or after the Delft Technological University was led by two theoretical physicists!

Meanwhile a second Technological University was started in Eindhoven in 1957, which offered Broer in 1961 a professorship in theoretical physics. Much to the regret of the Delft 'Technische Hogeschool' community, he decided to accept.

One of his main motives for accepting this chair in the newly founded university was the lack of a predecessor. Most people would be proud of stepping into a long tradition; Bert Broer thought it to be a great advantage not to have to reconcile to either a certain line of research or an existing curriculum. Especially the last circumstance is quite unusual and trying.

The task of teaching theoretical physics in a physics department is usually one at the core of the curriculum. Up to then the major part of the courses offered by him in Delft were not so central with a possible exception for the students in aeronautical engineering. In the center of his educational activity stood his main course in mathematical physics. If such a course is offered in a university it usually is done by a mathematician who tries to do physics all 
over again. It is proof of the quality of his teaching both as a physicist and an applied mathematician that the course also figured as an obligatory course in the curriculum for future mathematicians in Eindhoven.

On starting a line of research in Eindhoven it was his interest in mathematical methods that gave him a clue. Having a colleage in Eindhoven who was explicitly responsible for fluid dynamics, he wanted to keep clear of that subject now.

However, methods for the solution of quasi-linear equations were, as a matter of fact, very familiar to him. In the early sixties non-linear optical effects were being observed because of the availability of strong monochromatic sources. Broer realized that Maxwell's equations can be solved exactly in terms of simple waves along real characteristics, albeit at the price of neglect of dispersion $[66,72,74]$. The true nature of this type of solution, in contrast to perturbation type solutions, was only realized by the people in the field a considerable time later (e.g. Bloembergen). $\dagger$

However, throughout the Eindhoven years, the main line of thought was devoted to the application of the methods of theoretical mechanics to continuous systems. The first problem to inspire this approach originated quite naturally from the non-linear optical one by investigating the interaction of non-linearity and dispersion. As a testing ground served the rather unsystematic state of affairs with respect to the derivation of Boussinesq's equation for the propagation of surface waves in hydraulics $[73,75]$. The route went along more general discussions on linear wave propagation. In a series of articles together with Peletier $[78,79,80,83]$ the emphasis gradually shifts from stability studies to balance equations and then, with a restriction to conservative systems, to systems derivable from a Lagrangian density. Very clearly we see an ambition to study wave phenomena in a very general context. Many fragments of Broer's work from these years are to be found 'in the context of specialized fields of interest'. Broer tries and succeeds in building a framework that synthesizes many of the fragments into a comprehensive theory.

A new impulse comes from the discovery of conservation laws of the Lipkin zilch type (Lipkin 1964). Broer relates the number of independent zilches and conservation laws to the number of pairs of equal roots of the propagating matrix of the system [81]. From now on conservation laws and systems of conservation laws become a recurring theme. Broer's critical approach towards established practices in teaching mathematical physics leads him to consider the longitudinal motion of an elastic bar and the dynamics of strings $[85,87]$. Both papers exhibit the superiority of discussions of this type in terms of material coordinates, i.e. coordinates moving with the medium, although the fixed coordinates may have some advantages sometimes $[85]$.

$\dagger$ N. Bloembergen in Topics in nonlinear physics. Ed. N.J. Zabusky; Springer Verlag, 1968, pp. 425-484. 
In the meantime the preoccupation with methods of classical mechanics in relation to conservation laws was bearing more fruit. The collaboration with Kobussen should be mentioned here. A first result was of a didactic nature. On the basis of the Hamilton formalism the relation between invariant transformations and conservation laws is established. Then, on the basis of the Lagrangian formalism, the system is generalized to a continuous one and the relation with Noether's theorem is given in an extraordinary lucid way [86]. Further work led him to the following observation. Without dissipation the equation of motion of a continuous medium written in material coordinates, can rather easily be written in Lagrangian or Hamiltonian form. It occurred to Broer that this should also be the case in a fixed system of local coordinates, and that, conversion from material coordinates to local coordinates and vice versa can be considered as a canonical transformation [103]. The interest for canonical transformations for continuous systems had risen from the generalization to continuous systems of the well-known method of obtaining canonical transformations from generating functionals [98].

But the most interesting result which Broer obtained these last years is the concept of the hidden Hamiltonian [105]. The context of this work is the controversy over the alleged superiority of the Korteweg-de Vries equation over the Benjamin-Bona-Mahony equation or the other way around, both equations having advantages and disadvantages. The problem is usually discussed with the example of surface waves on water in the center or closeby $[106,109]$. As professor Miles treats this part of Broer's work in the sequel of this issue, we may remain silent about it here. But not without remarking that the theory can also be applied to stable approximations for ion-acoustic waves in plasma's [112].

A theme that is recurring with certain intervals in Broer's work is the propagation of waves in inhomogeneous media. One of his main contributions to the field [69] is due to his rather characteristic way of working. Thanks to his remarkable memory for the essentials of someone elses contribution Broer can afford to skip the trouble of retracing the exact place in the literature where to find that work. He simply uses what he thinks was the content of that contribution. When in the course of the subsequent publication the proper credit should be given and the original publication has been dug up, sometimes surprises are to be expected. One such remarkable surprise concerned the Bremmer series. The result was a different series that solves the Helmholtz equation exactly [69]. The relation between the terms of the Broer series and those of the Bremmer one was established somewhat later. In this relation the Fibonacci numbers due to Leonardo Fibonacci also known as Leonardo Pisano play a role [90]. This was, however, not the end of the story. More recently the work has seen an extension to nonmonochromatic solutions [111]. Especially the influence of the frequency on the convergence of the series is very interesting.

If by now the impression has taken ground that the Eindhoven years have 
seen Broer only as a scientist, we must make it clear that such an impression is wrong. First of all he has developed as a very productive teacher. Many theses were prepared and finished under his inspiring guidance. A remarkable number of his former pupils now hold themselves chairs in physics or mathematics in different universities. In Eindhoven Broer was not called to administrative duties of the same importance as in Delft. He had of course his share of the responsibilities and numerous were the occasions that people sought his wise advise based on his insight and his long experience in three universities with university administration. This does not mean that Broer did not have an open eye for the relations between physics and society. He was in fact the auctor intellectualis of the program for physics students willing to contemplate on this connection. The program became known under the name 'the naked science'. That this interest was not just a tribute to the fashion of the day can be proved from his Eindhoven oration [65]. Oddly enough the title of the oration was changed by the printer from: 'Growth and overgrowth of physics' (Groei en woekering der natuurkunde) to 'Growth and working of physics' (Groei en werking der natuurkunde), that way missing the point that was made. The oration was delivered in a period when funds for physics were lavish and competent personnel in high demand. New markets were opened to young physicists. As an example Broer mentions a field that was then in rapid expansion and gave hope to quick and dramatic fruits: plasma physics. Although even then, in 1962, most physicists were still quite optimistic, Broer spoke out his skepsis and evaluated the apparent overgrowth in this sector with its detrimental effects on other branches of physics. But what is most important, he showed what kind of research is most appropriate for universities. In fact, in the light of the present squeeze in funding and the abundance of competent physicists his lessons of 1962 should be reread.

A picture that aims to do justice to the man behind the physicist would not be complete without pointing to Broer's great erudition beyond physics. Although he never published on it, he has all the knowledge to tell us about the early Scandinavian history. How he came to know all this? A simple consequence of his ability to ask the right but unwonted question, as well in physics as outside of it. Suddenly in our history books the Swedes are there in the thirty year's war. Where did they come from, how could they all of a sudden be such a great power? The answer to that question can only be found by a study in depth of the history of those people right from their Viking ancestors. If you want to know, ask Broer! In this realm he can be a real match for the specialist. It has been a good thing for physics that he choose that as a career and not history. The historical and social interests of Broer, however, were the impetus to a remarkable scholarly contribution to the history of the engineering profession in the Netherlands. We mean the thesis by H.W. Lintsen that was fathered by Broer. We sincerely hope that there will be more to follow along this line.

The university has also benefited from Broer's interest and knowledge 
beyond the strict limits of his teaching assignment by having him teach courses in methodology of physics and history of physics. Both tasks were fulfilled with great expertise and ability. The university will have a hard time to find a worthy successor.

In conclusion we will point to one rather unusual feature in Broer's university career. Most university professors become less interested in science in the stricter sense and more interested in the administration of science in the course of their career. Not so with Broer. On the contrary. If it is sometimes maintained that people become scientifically less productive with growing age, then Broer is the counterexample who definitely defies the general character of such an allegation. Freed from all administrative duties we may expect an explosion of publications and certainly we hope that Broer will find time and opportunity to lay down his great contributions to the theory of wave propagation in a comprehensive monograph, so that this work will get its proper niche in the structure of physics.

\section{List of publications}

1. (1941) On the quantisation of electron wave functions. Physica 8: $321-336$.

2. (1942) On the high-frequency rest-susceptibility of Chromium alum. Physica 9: 547-555.

3. (1942) Negative result of an attempt to observe nuclear magnetic resonance in' solids (with C.J. Gorter).

Physica 9: 591-596.

4. (1943) Paramagnetic relaxation in two hydrated nickel salts (with L.J. Dijkstra and C.J. Gorter).

Physica 10: 324-330.

5. (1943) Paramagnetic dispersion at radiofrequencies in a few Gadolinium salts (with C.J. Gorter).

Physica 10: 621-628.

6. (1943) An apparatus for the study of paramagnetic dispersion at radiofrequencies (with D.C. Schering).

Physica 10: 631-643.

7. (1943) On the theory of paramagnetic relation.

Physica 10: $801-816$.

8. (1945) Beschouwingen en metingen over de paramagnetische relaxatie. Thesis University of Amsterdam.

9. (1945) Note on the theorie of vector wave fields (with A. Pais) Proc. Kon. Acad. 48: 190-197.

10. (1945) On the intensities and the multipole character in the spectra of the rare earth ions (with C.J. Gorter and J. Hoogschagen).

Physica 11: $231-250$.

11. (1946) On the interpretation of observations on the photoelectric 
voltages with intermittant light (with C.J. Gorter and A.P. Snoek). Physica 11: 401-411.

12. (1946) On the statistical mechanics in a magnetic field. Physica 12: 49-60.

13. (1946) De ontwikkelingsgang der stralingstheorie. Public Lesson, University of Amsterdam.

14. (1946) Theory of the electric depolarisation of Zeeman components. Physica 12: 639-641.

15. (1946) Atomic spectra in solids and solutions. Physica 12: 642-648.

16. (1947) Note on the theory of ionic association. Récueil des Trav. Chim. 66: 103-110.

17. (1947) Some further measurements on paramagnetic dispersion. Physica 13: 353-365.

18. (1947) Paramagnetic dispersion in some copper and silver salts (with J. Kemperman). Physica 13: 465-472.

19. (1947) Note on the gyromagnetism of superconductors and diamagnetic media.

Physica 13: $473-478$.

20. (1947) On the existence and uniqueness of the solution of the fundamental equation in the theory of metallic conduction.

Proc. Kon. Acad. 50: 396-402.

21. (1948) Spectroscopie met radiogolven. Jaarboek N.P.F. Amsterdam.

22. (1948) On the reflection-transmission effect in experiments on polarization of electrons.

Physical Review 2nd ser. 74: 1887-1888.

23. (1949) Note on the theory of the quadratic Zeeman effect in the Caesium spectrum.

Physica 14: 623-628.

24. (1949) On the hyperfine structure in Copper Tutton salts. Physica 15: 673-674.

25. (1949) Natuurwetenschap, Wiskunde en Maatschappij. Oration. Delft University of Technology.

26. (1950) On the propagation of energy in linear conservative waves. Appl. sci. Res. A2: 329-344.

27. (1950) On the influence of acoustic relaxation on compressible flow. Appl. sci. Res. A2: 447-468.

28. (1951) De beweging van een viskeuze vloeistof in een spleet met poreuze wanden.

De Ingenieur 63: W.61-W.65.

29. (1951) On the dynamical behaviour of a canonical ensemble. Physica 17: $531-542$. 
30. (1951) Niet-lineariteit en linearisering in de stromingsleer.

Ned. Tijdschr. v. Nat. 17: 281-300, Erratum 340.

30a. (1951) Een Laboratoriumproef met magnetohydrodynamische golven.

Ned. Tydschr. v. Nat. 17: 323-324.

31. (1952) On the theory of shock structure I. Appl. sci. Res. A3: 349-360.

32. (1953) Turbulentie in de Sterrekunde, Instabiliteit en turbulentie.

Ned. Tijdschr. v. Nat. 19: 50-60.

33. (1953) Note on the efficiency of thermal machines at a finite rate of expansion.

App. sci. Res. A4: 1-10.

34. (1953) Stromingsverschijnselen in cyclonen.

De Ingenieur 65: Ch. 77-Ch. 82 .

35. (1953) On the theory of shock structure II.

App. sci. Res. A4: 157-170.

36. (1954) Expansieverschijnselen in gassen I.

Ned. Tijdschr. v. Nat. 20: 205-220.

37. (1954) Pressure effects of relaxation and bulk viscosity in gas motion. Appl. sci. Res. A5: 55-64.

38. (1954) On the theory of shock structure III.

Appl. sci. Res. A5: 76-80.

39. (1954) On the theory of shock transition.

Colloque Junius Massau des Mémoires des Sciences 28(b): 37-41.

40. (1955) Die Bewegung kleinster Teilchen in Flüssigkeiten und Gasen.

VDI-Berichte 6: $41-42$.

41. (1955) Stromingsverschijnselen in meetapparatuur.

Reprint from Industriële volume- en stroommeting van gassen en vloei. stoffen.

42. (1955) Acoustische relaxatie.

Ned. Tijdschr. v. Nat. 21: 314-321.

43. (1955) Interpretatieproblemen bij dissipatieve processen.

Ned. Tijdschr. v. Nat. 21: 323-328.

44. (1956) Simple Wave Solutions of the Transonic Equation.

Journal of the Aeronautical Sciences 23: 287.

45. (1956) On the theory of the ventilation of traffic tunnels.

Appl. sci. Res. A6: 29-44.

46. (1956) On the hydrodynamics of visco-elastic fluids.

Appl. sci. Res. A6: 226-236.

47. (1956) A simple method for photographing transparent objects (with

A. Deeleman and J.A. Rietdijk).

Appl. sci. Res. B6: 253-258, Addendum B7: 184.

48. (1957) Uitschakelverschijnselen in lange waterleidingen.

De Ingenieur 69: 0.55-0.58. 
49. (1957) Some investigations on low-speed anemometry (with C.J. Hoogendoorn and A. Kortleven).

Appl. sci. Res. A7: 1-13.

50. (1957) Laminar flow of a visco-elastic fluid.

Comm. no. 84a from the Lab. for Aero- and Hydrodynamics of the Delft University of Technology.

51. (1958) Characteristics of the equations of motion of a reacting gas.

Journal of fluid Mechanics, 4: 276-282.

52. (1958) Total-head measurements in fluctuating flows (with R.E. de Haan).

Journal of Applied Mathematics and Physics (ZAMP) 9b: 162-172.

53. (1958) A heating mechanism in gas expansion.

Appl. sci. Res. A7: 476-478.

54. (1958) Toelatingsexamens van de T.H.D. op grond van buitenlandse diploma's.

Universiteit en Hogeschool 5: 62-71.

55. (1957) Wetenschap en Industrie, kontacten en legenstellingen. Wetenschap en Samenleving 11: 53-55,65-66.

56. (1959) Stromingsmetingen.

De Ingenieur 71: 0.69-0.80.

57. (1960) In het voetspoor van prometheus.

Public address on the occasion of the 118th dies natalis of the Delft University of Technology.

58. (1960) On the motion of a charged particle in an almost homogenous magnetic field (with L. van Wijngaarden).

Appl. sci. Res. B: 159-176.

59. (1960) A mechanical Hall effect. letter to the Editor (with L.A. Peletier and $L$. van Wijngaarden).

Appl. sci. Res. B: 259-260.

60. (1960) Het programma voor de studie voor werktuigbouwkundig Ingenieur aan de T.H.D.

Universiteit en Hogeschool 6: 517-523.

61. (1960) Motion of a charged particle in a Slowly Increasing Magnetic Field. Magneto-Fluid Dynamics.

Review of Modern Physics, 32: 742-743.

62. (1960) Mechanical Analogy of the Hall Effect.

Review of Modern Physics 32: 888.

63. (1960) Measurements on supersonic free jets (with J.A. Rietdijk). Appl. sci. Res. A9: 465-477.

64. (1961) Golven en golfgroepen.

Ned. Tijdschr. v. Nat. 27: 385-396.

65. (1962) Groei en werking van de natuurkunde.

Oration Eindhoven University of Technology. 
66. (1963) Exact solution of the Reflexion Problem in non-linear optics. Physics Letters, 4: 65.

67. (1962) Magnetohydrodynamic Flow along Wavy Walls (with L. van Wijngaarden).

Appl. sci. Res. B9: 451-469.

68. (1963) The impulsive motion of a wavy plate in a conducting fluid (with L. van Wijngaarden).

Appl. Sci. Res. B10: 91-109.

69. (1963) Note on Approximate solutions of the wave equation. Appl. sci. Res. B10: 110-118.

70. (1964) Grondslagen van de magnetohydrodynamische energie-omzetting. De Ingenieur 76: E37-E41.

71. (1964) Niet-lineaire optica.

Ned. Tijdschr. v. Nat. 30: 159-168.

72. (1964) On simple waves in non-linear dielectric media (with P.H.A. Sarluy).

Physica 30: 1421-1432.

73. (1965) On the interaction of non-linearity and dispersion in wave propagation. I. Boussinesq's Equation.

Appl. sci. Res. B1 1: 273-285.

74. (1965) Wave Propagation in Non-linear Media.

Journal of Applied Mathematics and Physics (ZAMP) 16: 18-26.

75. (1965) On the interaction of non-linearity and dispersion in wave propagation. II. Approximate solutions of the reduced Boussinesq equation.

Appl. sci. Res. B12: 113-129.

76. (1965) Introduction to general dynamical systems, stability and waves. Rijnhuizen Report 65-27.

Fom-Institute for Plasma Physics.

77. (1965) H. Görtler, ed. Applied Mechanics, Proc. of the 11th Int. Congr. of Applied Mechanics, Munich 1964, Berlin: Springer. Some recent advances in the theory of wave propagation pp. 59-68.

78. (1967) Some comments on linear wave equations (with L.A. Peletier). Appl. sci. Res. 17: 65-84.

79. (1967) On a class of conservative waves (with L.A. Peletier). Appl. sci. Res. 17: 133-149.

80. (1967) Some comments on linear wave propagation (with L.A. Peletier) in J. Brown, ed. Electromagnetic Wave Theory, Oxford: Pergamon pp. 85-94.

81. (1968) On the Zilch of plane waves.

Physica 38: $341-348$.

82. (1968) De Europese Natuurkundige Vereniging.

Ned. Tijdschr. v. Nat. 34: 161-164. 
83. (1969) Some properties of the solutions of wave equations (with L. A. Peletier).

Appl. sci. Res. 21: 138-161.

84. (1970) Some basic properties of relaxation gasdynamics. In P.P. Wegener (ed.)

Gasdynamics vol. 1 Part 2 Nonequilibrium Flows, New York: Dekker pp. $1-30$.

85. (1970) Longitudinal Motion of an Elastic Bar.

Journal of Eng. Math. 4: 1-7.

86. (1970) Behoudswetten en invariante transformaties (with J.A. Kobussen).

Ned. Tijdschr. v. Nat. 36: 34-62.

87. (1970) On the dynamics of strings.

Journal of Engineering Mathematics 4: 305-318.

88. (1970) On a simple wave approximation (with M.F.H. Schuurmans).

Journal of Engineering mathematics 4: 305-318.

89. (1971) On a unique continuum representation for the linear chain problem (with M.F.H. Schuurmans).

Physica 51: 493-502.

90. (1971) On some solutions of the wave equation (with J.B. v. Vroonhoven).

Physica 52: 441-454.

91. (1971) On a simple wave approximation to a non-linear problem (with M.F.H. Schuurmans).

Journal of Engineering Mathematics 5: 109-120.

92. (1971) Enkele opmerkingen over de beoefening van de natuurkunde.

Ned. Tijdschr. v. Nat. 37: 18-20.

93. (1971) Linear dynamical systems in Hilbert space (with $\mathbf{J}$. de Graaf) in H. Leipholz, ed. Instability of continuous systems, Berlin: Springer pp. 376-378.

94. (1972) Plane waves in linear homogeneous media I (with J. de Graaf).

Reports on Mathematical Physics 3: 43-75.

95. (1972) Plane waves in linear homogeneous media II (with J. de Graaf). Reports on Mathematical Physics 3: 109-138.

96. (1972) Plane waves in linear homogeneous media III (with J. de Graaf). Reports on Mathematical Physics 3: 139-155.

97. (1972) On a class of scattering equations (with M.F.H. Schuurmans). Appl. sci. Res. 26: 161-174.

98. (1972) Canonical transformations and generating functionals (with J.A. Kobussen).

Physica 61: 275--288.

99. (1973) Speculaties over toenemende verscheidenheid in het tertiaire onderwijs, in Verslag symposium Hoger Technisch Onderwijs in een veranderende samenleving, Eindhoven University of Technology. 
100. (1974) Note on constants of the motion.

Physica 72: 332-337.

101. (1974) Problemen rond de voortgezette studie in de natuurkunde in de U.S.A.

Ned. Tijdsch. v. Nat. 40: 238-240.

102. (1974) Generalized fluid dynamics and quantum mechanics.

Physica 76: 364-372.

103. (1974) Conversion from material to local coordinates as a canonical transformation (with J.A. Kobussen).

Appl. sci. Res. 29: 419-429.

104. (1974) On the hamiltonian theory of surface waves.

Appl. sci. Res. 29: 430-446.

105. (1975) Hidden Hamiltonians of first-order equations.

Physica 79A: 583-596.

106. (1975) Approximate equations for long water waves.

Appl. sci. Res. 31: 377-395.

107. (1976) On the momentum of potential waves.

Physica 83A: $471-485$.

108. (1976) Potential waves in one dimension (with S.C.M. Backerra).

Appl. sci. Res. 32: 495-507.

109. (1976) Stable model equations for long water waves (with E.W.C. v. Groesen and J.M.W. Timmers).

Appl. sci. Res. 32: 619-636.

110. (1977) Simple wave interation of an elastic string (with E.W.C. v. Groesen)

Rheologica Acta 16: 161-168.

111. (1978) Non-monochromatic solutions of the spatially inhomogeneous wave equation based on the WKB approximation (with Th.M.M. Verheggen and F.W. Sluijter).

J. Math. Anal. Appl. 62: 512-524.

112. (1977) Stable approximate equations for ion-acoustic waves (with F.W. Sluijter).

Phys. of Fluids 20: 1458-1460.

113. (1977) Approximations in the theory of ion-acoustic waves.

Journal of Appl. Sci. Eng. A2: 161-164.

114. (1978) On a proposed alternative to the $\mathrm{KdV}$ equation (with M. Lakshmanan).

Phys. Letters 66A: 173-174.

115. (1979) Some properties of wave equations in inhomogeneous media.

Radio Sci. 14: 245-251. 